\title{
Students' Perceptual Learning Style Preferences, Their Achievement, and Teachers' Teaching Styles (With Particular Reference to Tana Beles Girls' Boarding School, Pawe Woreda)
}

\author{
Pro.Abiy Gigzaw Tadesse Hirpa (M.Ed)
}

\begin{abstract}
This study aimed to identify the dominant students' learning styles preferences, their achievement, and teachers' teaching style preferences in Tana Beles Girls' Boarding School. Comparison was made between (i) students' perceptual learning style preferences' and their achievement. (ii) students' learning style preferences with respect to their teachers' teaching style preferences. The teaching styles and learning styles mentioned are based upon Reid (1987) consisting of visual, auditory, tactile, group, and individual. This study is a survey method using 4point Likert Scale questionnaire as the instrument. The obtained Cronbach alpha coefficients were 0.78 and 0.75 for teachers' and students' questionnaires respectively. Comprehensive sample technique was employed in the study. The data were analyzed using SPSS. Mean, standard deviation, ANOVA, Chi-square were used to detect the significances of the data. The result indicated that both students' learning styles and teacher's teaching styles did not match. The majority of students are group learners but the teachers preferred tactile teaching style.. Based on the findings, there were also the relationship between students' learning style preferences and their academic performances. This indicated that teaching styles can make students to promote their own learning success, which include a vast number of teaching techniques so as to make learning easier, fast, more enjoyable, effective, and to increase the performance. In the finding, students whose learning style was tactile scored good result since the teachers also preferred tactile teaching style. In all academic classrooms, no matter what the subject is, there are students with multiple learning styles. Everyday teachers thus should make instructional decisions before, during, and after meeting the students and these decisions should lead the teachers to adapted learning/teaching styles to accommodate all students in the classroom.
\end{abstract}

Keywords: learning styles, teaching styles, achievement

DOI: $10.7176 / \mathrm{JEP} / 11-10-05$

Publication date: April $30^{\text {th }} 2020$

Introduction

Many people recognize each person prefers different learning styles and techniques. Some students may find that they have a dominant style of learning, with far less use of the other styles. Others may find that they use different styles in different circumstances. The class of the students for one session may have very different learning styles from students in the next session. Some learning styles work better than others in different learning situations, but no one learning style is better than the other. Similar to this, Nunan (2003) described that everyone has different learning style profiles. However, some teachers do not consider students' learning style differences in the classroom for better understanding. As a result, they often teach students with the styles that they had experienced.

Most teachers would agree that each student is unique and has individual needs, likes, dislikes, accomplishments, and failures, as well as strengths and weaknesses. Although teachers agree that students learn in different ways, they do not attempt to assess and accommodate these differences. Students are often expected to fit into an established pattern of learning that commonly emphasized learning through visual and auditory. But students whose learning style preferences are tactile, group, and individual are discouraged and became less achiever in their academic performances (Gearheart et.al, 1988). Similarly, Williams and Burden (1997) pointed out that each learner is different, and brings to the learning process a unique set of personal characteristic, and preferred ways of learning. Learners make sense of the learning situation and learning tasks in ways that are personal and unique to them. The teachers, thus, need to provide a variety of language activities, which allow for different learning styles and individual preferences: some visual, some auditory, some involvement, some interactive, individualistic, and others cooperative. Although teachers believe that their students come to language classroom with different interests and preferences, they are still reluctant to consult learners in conducting language-learning activities. Felder (1996) stated that mismatches often occur between learning styles in students in a language class and the teaching style of the teacher with unfortunate effects on the quality of the students' learning

When mismatches exist between learning styles and the teaching style, the students may become bored and inattentive in class and get discouraged about the courses. Oxford et.at, cited in Zhenhui (2001), confirmed in their research that there are serious mismatches between learning styles and teaching styles. Wallace and Oxford, cited in Zhenhui (2001), also stated that such styles differences between students and teachers consistently and negatively affect students' grades. It is when students' learning styles are matched with appropriate approaches 
in teaching that their motivation, performances, and achievements will be increased and be enhanced. As Zhenhui (2001) indicated effective matching between teaching styles and learning styles can only be achieved when teachers are aware of their learners' needs, capacities, potentials and learning style preferences. Each teacher has his/her own preferred way of teaching that is determined by educational background and experiences (Reid, 1987).

Smih and Renzulli (1984) quoting Tyler et.al indicated many thoughts have been made regarding the existence of differences of learning styles among individual learners. Yet the fact of the matter seems to be that almost none are verified realities. Hart (1996) also stated that the survey research that has been conducted at secondary schools students' learning style preferences has not got due attention and it is not implemented in the classroom. That is why the researcher is eager to conduct a study on the students' learning style preferences and their match with teachers' teaching styles. Different researchers have conducted a survey regarding the learning style of EFL and ESL students. For instance, relating learning styles research with native speakers of English, Reid (1987), citing Witkin, Moore, Oltman et.al, and Grasha, suggested that students shift their major fields during their academic career that are well matched with their perceptual styles.

Generally, many researchers supported the idea that there are learning style preference differences among the learners in a class. However, there are controversies whether students' learning style preferences and achievement are aligned together. Although many researchers have been done on students' learning style preferences and achievements, there is not any research that has been conducted in a class of all males or all females. Thus, The following leading questions have been stated to see the students' major learning styles, teachers' major teaching styles, the relationship between students' learning style preferences and academic achievement, and the match between the learning styles and teaching styles in a class of only females:

* What are the students' major learning style preferences and teachers' major teaching style preferences?

* Is there a match between students' learning style preferences and teachers' teaching styles?

* Is there significant relationship between students' academic performances and their learning style preferences?

The purpose of this study is to survey the students' learning style preferences, their academic performance, and the match of learning styles and teaching styles. Thus, the specific objectives of the study are to:

$>$ See the students' major learning styles preferences and teachers' major teaching style preferences.

$>$ See the match between students' learning style preferences and teachers' teaching style preferences.

$>$ See the relationship between students' learning style preferences and their academic performances.

\section{Materials and Methods}

Participants of the research were all grade 9 and 10 students and all English teachers. The total number of students and teachers were 147 and 4 respectively. Since the numbers were easily manageable, all of them were taken as the participants. The students joined this boarding school after the completion of the primary education. They were students who did not have any opportunities to continue their education due to economic problem. Before they had come to this boarding school, most of them had already stopped learning. This program has been established by Benishangul Gumuz Regional State Education Bureau in order to help less-educated ethnic groups such as Gumuz, Mao, Komo, Berta, Shinasha, and some orphan students from other family. They almost belong to the same age group that ranges from 18-20. They were expected to be especial students because they were taught by the teachers who had good performance. Although they were from different ethnic members, they were familiar to one another. In fact, the influence of the culture on students' learning style preferences was indisputable and could not be controlled totally. Therefore, in this research cultural role on students' learning style preferences was not considered as a variable.

The numbers of the students and English teachers were manageable. Thus, the entire grade 9 and 10 students and all English teachers were included in the target group. Therefore, the sampling method was comprehensive. The instruments that were used in this study were language learning style preference questionnaire adapted from Reid (1987). Reid has developed learning style preference questionnaire particularly for learners of foreign language. The questionnaire assesses preferred learning styles of the students based on how they learn best using visual, auditory, tactile, individual, and group. The questionnaire consists of 35 selfreport items. Subjects were expected to indicate how much they agree with each item on a scale from 1 to 4 when they learn English. Each number noted certain measurement such as (4) strongly agree, (3) agree, (2) disagree and (1) strongly disagree. Questionnaire for the teachers was developed in the way that how they taught students whereas questionnaire for students was revised in the way that how they learned, studied, acted, or reflected. A pilot study was conducted to determine the suitability, validity and reliability of the items in the questionnaire. The obtained Cronbach alpha coefficients were 0.78 and 0.75 for teachers' and students' questionnaires respectively. The questionnaires were prepared by considering five learning style preferences such as auditory, tactile, visual, group, and individual. Both questionnaires had totally 35 items with seven items for each learning style category: visual $(7,8,12,15,26,28,34)$, tactile $(2,14,19,22,25,30,32)$, auditory $(1,3$, 
10, 11, 16, 20, 23), group $(4,5,6,18,24,27,29)$, and individual $(9,13,17,21,31,33,35)$.

One of the objectives of the research was to assess the relationship between students' academic achievement and their learning style preferences. To determine the relationship between achievements and learning styles, students' results were taken from the roster and arranged into five intervals based on Ministry of Education method of marking students' card. The following intervals were the values assigned for the students' achievement on the card: below $50 \%$ poor, $50-59 \%$ fair, $60-79 \%$ satisfactory, $80-89 \%$ very good, $90-100 \%$ excellent.

Before the questionnaire was distributed, the researcher explained the purpose of the study to the participants. The instructions to complete the questionnaire were presented orally in students' mother tongue like Gumuz, Shinasha, Mao, and Berta besides in Amharic and English. They were also informed that the items were completed individually. The instructions were given by the researcher and the third year English department students taken from Gilgel Beles CTE. Before the questionnaire was dispatched to individual participants, it was coded. The coded questionnaire was distributed to individual student in row. At the same time, the students were provided with the questionnaire to complete it with their learning style preferences. The researcher and the three assistants controlled and helped the students. After they had returned the questionnaire to the researcher, they were given attendance sheet to write their names in row. The attendance was taken to compare each student's response with her first semester EFL achievement on the roster. The data were analyzed by using different statistical techniques. The analysis included quantitative approaches in interpreting the data. Means, standard deviations, ANOVA, chi-square, Chi-square, and Tukey test were used. That is, ANOVA was used to see the existences of the significance differences among the means of the learning and teaching styles: visual, auditory, tactile, group, and individual. Tukey test was used to see which means differences showed significant value in both learning and teaching style preference. Chi-square was used to see the relation between learning style preferences and the students' achievement of EFL.

\section{Results and discussions}

Table-1 The means and standard deviations of students' responses on the learning style preferences

\begin{tabular}{|l|c|c|}
\hline \multirow{2}{*}{ Learning styles } & \multicolumn{2}{|c|}{ Total number of students $/ \mathrm{n}=130 /$} \\
\cline { 2 - 3 } & Mean $(\overline{\mathrm{X}})$ & Standard deviation \\
\hline Visual & 21.12 & 3.33 \\
\hline Auditory & 19.88 & 3.03 \\
\hline Tactile & 21.30 & 3.42 \\
\hline Group & 22.18 & 4.13 \\
\hline Individual & 19.62 & 3.72 \\
\hline
\end{tabular}

As it was indicated in the above table 1, students showed different preferences to learning styles. According to the mean score for each learning style, students favored group learning style. Sequentially, first group $(M=22.18)$, second tactile $(M=21.30)$, third visual $(M=21.12)$, forth auditory $(M=19.88)$, and fifth individual $(\mathrm{M}=19.62)$ learning styles were students' preferences. Their preferences to visual and tactile learning styles seemed more of similar. They also showed nearly similar preference toward auditory and individual learning styles. Moreover, the result from table 1 demonstrated that the standard deviation of students' preferences on visual, auditory, and tactile learning styles seemed almost similar whereas the standard deviation of group and individual learning styles seemed greater than others. This might indicate that the learners had different approaches toward group and individual learning styles. It is impossible to say really that the mean differences of the learning styles were significant by calculating only the means and standard deviations as it is indicated in the above table. Therefore, the means observed in the above table were also computed with ANOVA to see the significant differences among them. Hence, the purpose of using ANOVA was to compare the students' means of learning style preferences in order to decide whether there exists a statistically significant difference among them.

Table-2 ANOVA to determine the significant differences of students' learning style preference means.

\begin{tabular}{|l|c|c|c|c|c|}
\hline $\begin{array}{l}\text { Sources of } \\
\text { Variation }\end{array}$ & $\begin{array}{c}\text { Sum of squares } \\
(\mathrm{SS})\end{array}$ & $\begin{array}{c}\text { Degree of freedom } \\
(\mathrm{df})\end{array}$ & $\begin{array}{c}\text { Mean square } \\
(\mathrm{MS})\end{array}$ & $\mathrm{F}_{\text {ob. }}$ & $\mathrm{F}_{\text {cr. }}$ \\
\hline Between groups & 588.240 & 4 & 147.060 & 11.371 & 3.36 \\
\hline With groups & 8341.700 & 645 & 12.933 & & \\
\hline Total & 8929.940 & 649 & & \\
\hline
\end{tabular}

The decision about statistically significant difference between the means was made by comparing the observed F with the critical value of F. In the above table the observed F (11.371) exceeded the critical F (3.36) with 4 and 645 degrees of freedom at 0.01 level of confidence. At $99 \%$ level of confidence there was evidence 
from the sample data that the mean scores for the learning style preferences were different overall. Thus, the conclusion was that, the table indicated statistically significant differences between the means of the learning style preferences of the students. The mean differences of learning style preferences showed that students have different approach towards the learning styles. Although there was a significant difference among the means, at this point, it was difficult to know which mean differs significantly from the others. To exactly know which means differ significantly from others, there were multiple comparisons of means in the following table.

Table-3 Multiple comparison of means of students' learning style preferences by Tukey

\begin{tabular}{|l|l|c|c|}
\hline \multicolumn{2}{|c|}{ Learning styles } & Mean differences & P-value \\
\hline \multirow{3}{*}{$\mathrm{X}_{1}=21.12$} & $\overline{\mathrm{X}}_{2}=19.88$ & $1.24 *$ & 0.043 \\
\cline { 2 - 4 } & $\overline{\mathrm{X}}_{3}=21.30$ & 0.18 & 0.995 \\
\cline { 2 - 4 } & $\overline{\mathrm{X}}_{4}=22.18$ & 1.06 & 0.122 \\
\cline { 2 - 4 } & $\overline{\mathrm{X}}_{5}=19.62$ & $1.50 *$ & 0.007 \\
\hline \multirow{3}{*}{$\mathrm{X}_{2}=19.88$} & $\overline{\mathrm{X}}_{3}=21.30$ & $1.42^{*}$ & 0.013 \\
\cline { 2 - 4 } & $\overline{\mathrm{X}}_{4}=22.18$ & $2.30^{*}$ & 0.000 \\
\cline { 2 - 4 } & $\overline{\mathrm{X}}_{5}=19.62$ & 0.26 & 0.977 \\
\hline$\overline{\mathrm{X}}_{3}=21.30$ & $\overline{\mathrm{X}}_{4}=22.18$ & 0.88 & 0.275 \\
\cline { 2 - 4 } & $\overline{\mathrm{X}}_{5}=19.62$ & $1.68^{*}$ & 0.002 \\
\hline$\overline{\mathrm{X}}_{4}=22.18$ & $\overline{\mathrm{X}}_{5}=19.62$ & $2.56^{*}$ & 0.000 \\
\hline
\end{tabular}

Significance level at $\mathrm{P}<0.05$

$\left(\overline{\mathrm{X}}_{1}, \overline{\mathrm{X}_{2}}, \mathrm{X}_{3}, \mathrm{X}_{4}, \overline{\text { and }} \mathrm{X}_{5}\right.$ the means of visual, auditory, tactile, group, and individual learning style preferences respectively)

As it was indicated in the above table, the comparison among the means of the learning styles is significant at $\mathrm{P}<0.05$. This shows that any of the mean differences that are greater than or equal to 1.217 are significant at $\mathrm{P}<0.05$ with 645 degrees of freedom. Therefore, from table 3 , it could be concluded that the mean differences between visual and auditory, visual and individual, auditory and tactile, auditory and group, tactile and individual, and group and individual are significant. On the other hand, the significant differences were not observed between visual and tactile, visual and group, auditory and individual, tactile and group. The highest mean difference was observed between group and individual learning styles and the second was observed between group and auditory.

Generally, the significant differences between the means indicated that students' preferences were group learning style at most and then they show almost equal preference toward tactile and visual learning styles.

The relationship between students' learning style and academic achievement

To determine the relationship between students' academic achievement and learning styles, the students' first semester results were arranged into five intervals based on Ministry of Education method of marking. That is, below $50 \%$ poor, $50-59 \%$ fair, $60-79 \%$ satisfactory, $80-89 \%$ very good, $90-100 \%$ excellent. To compute this relationship chi-square was used as indicated below in table 4.

Table-4 The relationship between students' learning style preferences and academic achievement in chi-square test

\begin{tabular}{|c|c|c|c|c|c|c|}
\hline \multirow[t]{2}{*}{ Learning styles } & \multicolumn{5}{|c|}{ Academic achievement } & \multirow[b]{2}{*}{ Total } \\
\hline & $<50$ & $50-59$ & $60-79$ & $80-89$ & $90-100$ & \\
\hline \multirow[t]{2}{*}{ Visual } & $0(0 \%)$ & $9(36 \%)$ & $13(52 \%)$ & $3(12 \%)$ & $0(0 \%)$ & \multirow[t]{2}{*}{25} \\
\hline & $0.384 *$ & $10.000 *$ & $12.692 *$ & $1.923^{*}$ & $0.000^{*}$ & \\
\hline \multirow[t]{2}{*}{ Auditory } & $2(18.18 \%)$ & $2(18.18 \%)$ & $7(63.63 \%)$ & $0(\%)$ & $0(0 \%)$ & \multirow[t]{2}{*}{11} \\
\hline & $0.169 *$ & $4.400 *$ & $5.584 *$ & $0.846^{*}$ & $0.000 *$ & \\
\hline \multirow[t]{2}{*}{ Tactile } & $0(\%)$ & $9(45 \%)$ & $6(30 \%)$ & $5(25 \%)$ & $0(0 \%)$ & \multirow[t]{2}{*}{20} \\
\hline & 0.307 & $8.000 *$ & $10.153 *$ & $1.538^{*}$ & $0.000 *$ & \\
\hline \multirow[t]{2}{*}{ Group } & $0(0 \%)$ & $22(37.28 \%)$ & $36(61.01 \%)$ & $1(1.69 \%)$ & $0(0 \%)$ & \multirow[t]{2}{*}{59} \\
\hline & $0.907 *$ & $23.600 *$ & $29.953 *$ & $4.353 *$ & $0.000 *$ & \\
\hline \multirow[t]{2}{*}{ Individual } & $0(0 \%)$ & $10(66.66 \%)$ & $4(26.66 \%)$ & $1(6.66 \%)$ & $0(0 \%)$ & \multirow[t]{2}{*}{15} \\
\hline & $0.230 *$ & $6.000 *$ & $7.615^{*}$ & $1.153 *$ & $0.000 *$ & \\
\hline Total & 2 & 52 & 66 & 10 & 0 & 130 \\
\hline
\end{tabular}

As it was summarized above in table 4, students' achievements were arranged from poor to excellent. The largest numbers of students (59) among the population were found in group learning style row whereas the least number of students (11) were observed in the row of auditory learning style. To see the relationship between students' preference and achievement comparison was made between critical and observed values of chi-square. The critical value of chi-square with 16 degrees of freedom at 0.01 level of confidence was 32.000 whereas the 
computed value of chi-square was 42.946. Since the computed value (42.946) exceeded the critical value (32.000), there was significant relationship between students' learning style preferences and achievements. This showed that if students did not learn by their own preferences of learning styles, their achievement would be low. The preference of most students was group learning style and this also showed that there was significant relationship of learning style preference with academic achievement. The students' second preference, tactile learning style, also showed the significant relation with their academic achievement.

The table showed that nobody achieved excellent in all learning styles. Even though the largest numbers of learners (59 students) prefer group learning style; nobody entered in the excellent (90-100\%) intervals. Only one or $1.69 \%$ of group learners score was in very good $(80-89 \%)$ intervals. The majority of group learners $(36$ students or $61.01 \%)$ learners' achievements lied in satisfactory (60-79\%) intervals and $22(37.28 \%)$ of group learners achievements were in fair intervals (50-59\%). Here also there were $3(12 \%)$ visual learners achieve scores in the intervals of very good (80-89\%) and $13(52 \%)$ of visual learners' scores were in the intervals of satisfactory $(60-79 \%)$. On the other hand, tactile learning style was the second preference of the students. Students who were tactile learners achieved better scores than the students who preferred the other types of learning styles. As it was indicated in the above table 4, the largest number of learners; that is, $5(25 \%)$ of tactile learners' scores were in the intervals of very good (80-89\%). The least numbers of students (11 students) preferred auditory learning style. The students who were auditory learners achieved the least score as it was indicated in table 4. There were not any students among auditory learners whose scores were in the intervals of excellent or very good. The least scorers belonged to students whose preference was auditory learning style. That is, as it was shown in table 4 above there were $2(18.18 \%)$ of auditory learners whose scores were in poor intervals $(<50 \%)$

Generally, from the total students, none of the students' scores were in the intervals of excellent (90-100\%), $7.69 \%$ students scores were in the intervals of very good (80-89\%), 50.76\% students' scores were in the intervals of satisfactory (60-79), 40\% students scores were in the intervals of fair (50-59\%), and $1.53 \%$ students' scores were in the intervals of poor $(<50 \%)$. The cause for students' low achievement might be inconsistency of their learning style preferences with teachers' teaching styles in the actual classroom.

\section{Teachers' responses to teaching style preferences}

One of the objectives of this research was assessing teachers' teaching style preferences to see whether they match with students' learning style preferences. To determine this descriptive statistics (mean and standard deviation) were used as indicated below in the table.

Table- 5 The means and standard deviations of teachers' responses on the teaching style preferences

\begin{tabular}{|l|c|c|}
\hline \multirow{2}{*}{ Teaching styles } & \multicolumn{2}{|c|}{ Total number of teachers/n=4/ } \\
\cline { 2 - 3 } & Mean $(\overline{\mathrm{X}})$ & Standard deviation \\
\hline Visual & 21.25 & 1.89 \\
\hline Auditory & 17.50 & 2.08 \\
\hline Tactile & 23.75 & 1.71 \\
\hline Group & 23.00 & 1.83 \\
\hline Individual & 21.00 & 3.16 \\
\hline
\end{tabular}

As it was shown in table 5 above, there were differences among teachers in their teaching styles. The means of teachers' teaching styles showed that tactile $(M=23.37)$, group $(M=23)$, visual $(M=21.25)$, individual $(M=21)$, and auditory $(\mathrm{M}=17.50)$ were the prioritized teaching styles respectively. As it was observed, teachers gave almost equal value to visual and individual teaching styles. The auditory teaching style was the least favored by the others.

There were not significant differences among the standard deviations of visual, group, and tactile teaching styles as shown in the above table. This implied that teachers have almost similar approaches to those teaching styles. On the other hand, the standard deviation of individual teaching style showed significant difference from the others. This showed that there were great differences among teachers toward individual teaching style. Similarly, the standard deviation of auditory teaching style indicated that there were significances different among teachers to use this teaching style.

Table-6 A summary table for ANOVA to determine the significant differences of teachers' teaching style preference means

\begin{tabular}{|l|c|c|c|c|c|}
\hline $\begin{array}{l}\text { Sources of } \\
\text { Variation }\end{array}$ & $\begin{array}{c}\text { Sum of squares } \\
(\mathrm{SS})\end{array}$ & $\begin{array}{c}\text { Degree of freedom } \\
(\mathrm{df})\end{array}$ & Mean square(MS) & $\begin{array}{c}\text { F } \\
\text { observed }\end{array}$ & $\begin{array}{c}\mathrm{F} \\
\text { Critical }\end{array}$ \\
\hline Between groups & 93.700 & 4 & 23.425 & 4.847 & 3.06 \\
\hline With groups & 72.500 & 15 & 4.833 & & \\
\hline Total & 166.200 & 19 & & & \\
\hline
\end{tabular}

Significance level at $\mathrm{P}<0.05$ 
As it was indicated above in table 6, the observed F (4.847) exceeds the critical F (3.06) with 4 and 15 degree of freedom at 0.05 level of confidence. Therefore, there were significant differences among the teachers' teaching style means. Thus, the conclusion was that there were differences among the teachers in implementing visual, auditory, tactile, group, and individual teaching styles.

Table-7 Multiple comparison of the five means of teachers' teaching style preferences by Tukey test

\begin{tabular}{|l|l|c|c|}
\hline \multicolumn{2}{|c|}{ teaching styles } & Mean difference & P-value \\
\hline \multirow{3}{*}{$\bar{X}_{1}=21.25$} & $\overline{\mathrm{X}}_{2}=17.50$ & 3.75 & 0.165 \\
\cline { 2 - 4 } & $\overline{\mathrm{X}}_{3}=23.75$ & 2.50 & 0.515 \\
\cline { 2 - 4 } & $\overline{\mathrm{X}}_{4}=23.00$ & 1.75 & 0.791 \\
\cline { 2 - 4 } & $\overline{\mathrm{X}}_{5}=21.00$ & 0.25 & 1.00 \\
\hline \multirow{3}{*}{$\overline{\mathrm{X}}_{2}=17.50$} & $\overline{\mathrm{X}}_{3}=23.75$ & $6.25 *$ & 0.008 \\
\cline { 2 - 4 } & $\overline{\mathrm{X}}_{4}=23.00$ & $5.50 *$ & 0.021 \\
\cline { 2 - 4 } & $\overline{\mathrm{X}}_{5}=21.00$ & 3.50 & 0.214 \\
\hline$\overline{\mathrm{X}}_{3}=23.75$ & $\overline{\mathrm{X}}_{4}=23.00$ & 0.75 & 0.988 \\
\cline { 2 - 4 } & $\overline{\mathrm{X}}_{5}=21.00$ & 2.75 & 0.425 \\
\hline $\mathrm{X}_{4}=23.00$ & $\mathrm{X}_{5}=21.00$ & 2.00 & 0.703 \\
\hline
\end{tabular}

Significance level at $\mathrm{P}<0.05$

$\left(\overline{\mathrm{X}}_{1}, \mathrm{X}_{2}, \overline{\mathrm{X}}_{2}, \overline{\mathrm{X}}_{4}\right.$, and $\overline{\mathrm{X}}_{5}$ the means of visual, auditory, tactile, group, and individual teaching style preferences) The above table indicated that any of the mean differences that were greater than or equal to 4.803 were significance at $\mathrm{P}<0.05$ level of confidence with 15 degree of freedom. Thus, from table 7 it was seen that the mean differences between auditory and tactile, and between auditory and group teaching styles greater than the computed value. So, here it could be said that the teaching styles that significantly differ from the rest of the teaching styles were auditory with tactile and auditory with group teaching styles.

Table-8 Comparison of each student's and teacher's preferences of learning /teaching/ styles

\begin{tabular}{|c|c|c|c|c|c|c|}
\hline \multirow[b]{2}{*}{ Respondent } & \multicolumn{5}{|c|}{ Learning /teaching/ styles } & \multirow[b]{2}{*}{ total } \\
\hline & Visual & auditory & Tactile & group & individual & \\
\hline Students & $\begin{array}{c}25 \\
19.23 \%\end{array}$ & $\begin{array}{c}11 \\
8.46 \%\end{array}$ & $\begin{array}{c}20 \\
15.38 \%\end{array}$ & $\begin{array}{c}59 \\
45.38 \%\end{array}$ & $\begin{array}{c}15 \\
11.53 \%\end{array}$ & 130 \\
\hline Teachers & $\begin{array}{c}0 \\
0 \%\end{array}$ & $\begin{array}{c}0 \\
0 \%\end{array}$ & $\begin{array}{c}3 \\
75 \%\end{array}$ & $\begin{array}{c}1 \\
25 \%\end{array}$ & $\begin{array}{c}0 \\
0 \%\end{array}$ & 4 \\
\hline
\end{tabular}

As indicated in the above table, there were differences between teachers and students in giving value to each style. $59(45.38 \%)$ students gave priority to group learning style; $25(19.23 \%)$ students preferred visual learning style; $20(15.38 \%)$ students were tactile learners; $15(11.53 \%)$ students were individual learners; and only $11(8.46 \%)$ students were auditory learners. On the other hand, $3(75 \%)$ teachers preferred tactile teaching style and only $1(25 \%)$ teachers preferred group teaching style.

As mentioned above, the purposes of the study were to assess the major learning and teaching styles of both teachers and students, and to see the relationship between students' learning style preferences and their academic achievement. To investigate these purposes, descriptive statistics was implemented. As data were read in table 1 , the students' learning style preference means yielded the following results: group $(M=22.18)$, tactile $(M=21.30)$, visual $(M=21.12)$, auditory $(M=19.88)$, and individual $(M=19.62)$. The dominant learning style preferences were group, tactile and visual respectively. On the other hand, minor leaning style preferences were individual and auditory. At $\mathrm{P}<0.01$ level of confidence, there is evidence from the sample data that the mean scores for the learning style preferences were different.

As it was indicated in table 2, F observed (11.371) exceeded F critical (3.63) with 4 and 645 degree of freedom at $\mathrm{P}<0.01$ level of confidence. Thus, here the conclusion was there were statistically significant differences between the means of the students' learning style preferences: visual, auditory, tactile, group, and individual. As it was indicated in table 3, the mean differences were significant where $\left(\mathrm{X}_{\mathrm{i}}-\mathrm{X}_{\mathrm{K}}\right) \geq 1.217$. Based on this restriction the significant mean differences were valid between the means of visual and auditory (1.24), visual and individual (1.50), auditory and tactile (1.42), auditory and group (2.30), tactile, and individual 1.68), and group and individual (2.56). From the above expressions, it could be concluded that each student had personal and unique learning style approach. Some of these styles were evident in clearly different preferences with respect to variables like styles to studying, and preferences for specific instructional methods. Similar to this, Lefrancois (2000) indicated that students learn in different ways that each student has a unique learning style. Some learners have a marked preference for the visual or the auditory mode; some respond better than others to praise. Similarly, Dunn and Griggs, cited in Lefrancois (2000), explained some students do their best work individually. Some do extremely well with highly visual and teacher-directed instructional methods. Some students want to be held what to do, when to do, and how to do it; others perform best when working on their own initiative. 
The finding in table 5 indicated that teachers principal preference were tactile $(M=23.75)$, followed by group $(M=23.00)$, next visual $(M=21.25)$, then individual $(M=21.00)$, and finally auditory $(M=17.50)$. Thus, the teachers' major learning styles were tactile, group, and visual. As it was indicated above in table 6, the observed $\mathrm{F}$ (4.847) exceeds the critical F (3.06) with 4 and 15 degree of freedom at $\mathrm{P}<0.05$ level of confidence. This indicated that there were statistically significance differences among the means of the teachers' teaching styles. Also the finding in table 7 showed that significant mean differences were obtained at $\left(X_{i}-X_{K}\right) \geq 4.803$. Thus, the significantly mean differences were seen between auditory and tactile; between auditory and group teaching styles.

When the means of students' and teachers' styles were compared, there were differences between them. Mean scores for both were observed differently, which means that students privileged first group followed by tactile and then visual learning styles when compared with teachers' teaching styles that was tactile came first and followed by group, and then visual. Similarly, individual student and teacher choices of styles were scrutinized in table 8 . As it was indicated 59 students or $45.38 \%$ of students from the total gave priority to group learning style where as 3 teachers or $75 \%$ of teachers from the total preferred tactile teaching style. Regarding the second choices of both teachers and students, $25(19.23 \%)$ students prefer visual learning style from the whole students; whereas only $1(25 \%)$ teacher prefers group teaching style. $20(15.38 \%)$ students were tactile learners, $15(11.53 \%)$ students were individual learners, and only $11(8.46 \%)$ students were auditory learners. There were not any teachers who gave priority to visual, auditory, and individual teaching styles as shown in table 8 . Thus, here it could be concluded as there were mismatch between students and teacher in favoring styles. Oxford et.al, cited in Zhenhui (2001), confirmed in their research that there are serious mismatches between the learning styles of students and the teaching style of the teachers. Alike to this, Spratt, cited in Riazi and Riasati (2007:203) showed a considerable lack of correspondence between learners' and teachers' preference and 'it was seen that teachers' perceptions of learners' preferences correspond in approximately 50\% of cases with learners' actual preferences.'”

Similarly, Gearheart et.al (1988) explained that although teachers generally agree that students learn in different ways, they do not always attempt to assess and accommodate these differences. Students are often expected to fit into an established pattern of learning styles that were commonly emphasized, and students whose learning style preferences were different from that of teachers' styles were discouraged and achieved low mark in their academic performances. Similarly, Felder (1996) also stated that mismatches occur between learning styles and teaching styles. Teachers, therefore; need to discover their students' preferred ways of learning the language. They can teach in a way that engages to students and do what works best for them. Williams and Burden (1997) also pointed out that each learner was different, and will bring to the learning process a unique set of personal attributes and preferred ways of learning. Teachers, thus, need to provide a variety of language activities, which allow for different learning styles and individual preferences and personalities: some visual, some auditory, some involvement, some interactive and some analytic.

Despite the fact that the school was to all girls students, there were not female English teachers. That is, the learners were all females whereas the English teachers were all males. Thus, the disparities of preferences between students and teachers styles might be due to the gender differences. Although the reason for the differences was controversial, there was evidence that males and females tend to approach learning /teaching/ from a different perspective. Supporting this idea, Hanson and Schwartz (1992) stated that in the classroom females prefer to use a conversation style that fosters group discussion and builds ideas on top of each other; the interaction of thoughts was dominant. Males, on the other hand, learn through argument and working on activities. Ong, cited in Hanson and Schwartz (1992), also stated that most classroom discourse is organized to accommodate male learning pattern. In a class female students' participation was observed less. Severiens and Ten Dam (1997:1) explained that "one of the most striking differences between female and male students in education concerns the choices females and males make to prefer particular styles." Considering the fact that girls' school led to less opportunities in the labor than those of males, it was important to search for factors which are related to the learning styles choices of females.

Hendrich and Strange (1989) stated that when female students do participate in a classroom, their approaches were considered as they have less command over the subject matter. Furthermore, Hendrich and Strange (1989) indicated in their research findings that girls were more likely to ask questions, acknowledge the comments of previous speakers, and refrain from interrupting interactions among themselves. Teachers were apt to treat females' discourse contributions with less respect because girls exhibited less authority. In allowing classroom discourse to similar sex-role differences in the classroom, teachers unconsciously passed on negative expectations for girls. Capel et.al (2001) identified that it was important to be aware that classes contain pupils whose habitual learning styles vary. Teachers need to ensure that they provide a variety of media in which pupils could work and be assessed. Learning styles involve educating methods, particular to an individual that were presumed to allow that individual to learn best. It was commonly believed that most people favor some particular method of interacting with, taking in, and processing stimuli or information. Teachers should assess the learning 
styles of their students and adapt their classroom methods to best fit each student's learning style.

In order to accommodate different learning styles in the classroom, teachers need to take into consideration, for example, that visual learners prefer reading, observing, and more data for their interpretation or more visual aids, such as, diagrams, pictures, graphs. Tactile learners prefer doing or hands-on experience to create and develop what they learn. They learn best from the trial and error experiences. Auditory students prefer more listening to the lectures and seminars, and participating in discussions. These students like to listen to the tape recordings of material and have a chance to ask questions about what they have learned or do not understand. Group oriented learners acquire knowledge best when they study with one or more students in a group. Individual oriented learners learn best when they learn alone. Information is easily acquired if she is left alone to study or work on any project. Information is best remembered when the learning has taken place in quiet environment and if the learner studies alone. Teachers who accommodated learning styles in their interactions with learners were found to foster greater learner achievement and more positive attitudes towards their subjects. Therefore, teachers inevitably implement different learning styles in a class to fit with different students.

The relationship between students' academic achievement and learning style preferences was indicated in table 4. The calculated value of chi-square was 42.980 and the critical value of chi-square with 16 degree of freedom and at $\mathrm{P}<0.01$ level of confidence was 32.00. Since the calculated value exceeded the critical value, there was strong relationship between learning style preferences and students' academic performances. As it was indicated in table 4, among 130 students 118 (90.76\%) students' achievements were in the intervals of 50-79\%. That is, they were in fair and satisfactory remarks. Only $10(7.69 \%)$ students achieved in the interval of 80-89\% or very good remark. $2(1.53 \%)$ students scored below $50 \%$ or they were poor scorers. Nobody scored in the interval of $90-100 \%$ or excellent remark. As it was indicated in table 4, students who preferred tactile learning style achieved better result. The largest numbers of students who scored in the intervals of very good (80-89\%) were also tactile learners. There were 5 students who scored in this interval. This was due to the matching of their learning style preferences with that of teachers' teaching styles. There was evidence that students achieve low scores when their preferences do not align with teachers' styles. Oxford and Lavine, cited in Shrum and Glisan (2000: 258), claimed that "students whose learning styles resemble that of teachers' are more likely to achieve better grades than the students whose learning styles do not resemble that of teachers' teaching styles." As teachers and students become aware of their major learning style preferences, they may be able to help one another. Lefrancois (2000), citing Dunn and Stevenson said that most students tend to do better when they are allowed to use their personal learning styles. Corder, cited in Bada and Okan (2000), also stated that the end successful of language teaching-learning is going to be dependent upon students' learning style preferences, interaction, and participation in the classroom.

According to Felder (1996), to achieve a desired learning outcome, teachers should provide activities that were well-matched with the ways through which learners like to learn the language. When mismatches exist between learning styles and teaching style, the students may become inattentive in class and get discouraged. Wallace and Oxford, cited in Zhenhui (2001), showed that style differences between students and teachers negatively affect student grades. Therefore, as Zhenhui (2001) stated, effective matching between teaching styles and learning style can only be achieved when teachers are aware of their learners' needs, capacities, potentials and learning style preferences.

According to Elliott (2000), styles give teachers practical means of identifying students' style, thus improving the ability to match students' preferences with the teachers' method. Ford and Chen (2001) explored the relationship between matching and mismatching of instructional presentation styles with students' styles. The results suggest that the matched group had better performance than the mismatched group. Teaching and learning styles should be of the greatest interest to educators, particularly the relationship between the two. Felder (1996) also showed that matching teaching styles to learning styles can significantly enhance academic achievement, students' attitudes and behavior at the primary and secondary school level, and specifically in foreign language learning institution. Similarly, Reid (1987) explained that matching teaching styles with learning styles give all learners an equal chance in the classroom and builds students self-awareness. Being more aware of how to approach tasks and how to do it as effectively as possible learning styles and teaching styles must match to obtain a good student's and teacher's performance in the classroom. A match between teaching and learning styles in language classroom creates a motivating environment that aids the learning and teaching processes.

\section{Recommendations}

As it was mentioned above, the basic objectives of this research were to search major learning and teaching styles, to see the relation between the learning style preferences and academic achievement, and the match between learning styles and teaching styles. The finding indicated that there was mismatch between learning styles and teaching styles. Students' major learning styles were group, tactile, and visual; whereas teachers' major teaching styles were tactile, group, and visual respectively. There was strong significant relationship 
between students' learning style preferences and academic achievement. Students whose learning style preferences matched with teachers' teaching styles scored good result. Based on these findings, the following recommendations were suggested:

Teachers should encourage students to their confidence by using communicative approaches and give them more active practices in their own learning styles. Individual differences of students need to be considered and the instructional delivery system needs to correspond to the varying abilities of the students. Teachers should take into consideration differences among the students when designing the lesson. Students should also be advised to try to adjust to different learning circumstances in order to avoid any disagreements when exposed to learning styles that does not suite them. Further research into learning styles should be carried, as the area is very broad and the issue can be approached from many different perspectives. Learning styles of the students are one of many factors that should be considered when researching student's attitudes and achievements. The students should be also made aware of their learning style preferences. Students should also take for granted that their learning styles are habitual. Teachers should adopt more of students' centred approaches in their teaching. In doing so, they need to carefully plan their lessons by incorporating more students' participation in the classroom activities and at the same time making sure that they are there to facilitate the students.

Teachers should also vary their teaching styles to a higher degree towards the teaching styles to accommodate the majority request of the students. The students must be also willing to build relationships with the capability to learn in new ways and the teachers must be willing to teach them how to do so. This finding suggests a positive input toward the considerations and planning of the teaching styles to be adopted in the classroom by the teachers. Moreover, the English Language teachers should worry about gender cases besides focusing on others factors such as various activities appealing to the students relevant to the preferred teaching styles stated by them. The teacher must also conduct a survey research in their schools to identify students leaning style preferences in order to equip the learners with necessary skills and to teach them with their preferences and with more confidence. Further research into learning and teaching styles is also recommended as this issue can be approached from many different perspectives. The current study was based solely on single-sex classes or all-girls boarding school perspectives. A similar study should also be conducted on comparison between male students' and female students' learning style preferences in order to make generalizations applicable to other schools.

\section{References}

Bada, Z.and Okan, Z. (2000).Students' Language Learning Preferences. Retrieved on Jan.10, 2010 from Journal, Vol.4 No.3 May.Turky: Cukuova University.

Capel, S. et al (2001).Learning to teach in the Secondary School: A Composition to School experience. Great Britain: Bell and Bain Ltd.

Elliott, N.S. et.al. (2000). Educational Psychology. U. S. A.: McGraw-Hill. Companies Inc.

Felder, R.M. (1996). Matters of styles. American Society for Engineering Education Prism, 6(4), $18-23$. Retrieved on Dec.1, 2010 from http://www2.ncsu.edu/unity/lockers/users/f/felder/public/Papers/LSPrism.htm.

Gearheart, R.B.et.al. (1988). The Exceptional Student in the Regular Classroom. U .S. A: Merrill Publishing Company.

Hart, S. (1996).Differentiation and the Secondary Curriculum. New York: Routedge.

Hendrich, J. and Strange, T. (1989).Do actions speak louder than words? Effects of the functional use of language on dominate sex role behavior in boys and girls. Norman: Oklahoma University Press.

Lefrancois, R. (2000). Psychology for teaching .U.S.A: Wadsworth, a division of Thomson.

Nunan, D. (2003).Practical English Language Teaching (ed). U. S. A.: The McGraw-Hill Companies Inc.

Reid, J. M. (1987). The learning style preferences of ESL students. Retrieved on Jan.10, 2010 from TESOL Quarterly, Vol. 21, No.1.

Riazi, A. and Riasati, J.M. (2007). Language Learning Style Preferences. Students Case Study of Shiraz EFL Institutes: Retrieved on March 29, 2010 from the Asian EFL Journal Quarterly Volume 9, Issue 1.

Severiens, S.A. and Ten Dam, G. (1997).Gender and Gender identity differences in learning styles. Retrieved on Jan. 10, 2010 from Educational Psychology, Vol. 17, No. 1 and 2. http://dare.uva.nl/document/44649.

Shrum, J.L. and Gilsan, E.W. (2000).Teachers hand book: Contextualize Language Instruction. (2 ${ }^{\text {nd }}$ ed.).Boston: Heinlein, a division of Thomson Learning, Inc.

Smih, L. and Renzulli, J. (1984).Learning style Preference: A Practical approach for classroom teacher. Retrieved on Apr. 19, 2010 from. Theory into Practice 23:45-50

Williams, M. and Burden, L.R. (1997).Psychology for Language Teaching. A social constructivist Approach. Cambridge: Cambridge University Press.

Zhenhui, R. (2001). Matching teaching styles with learning styles for ESL/EFL instruction. Retrieved on March 29, 2010 from The internet TESL Journal, Vol.VII, No.7 